\title{
Aprendizaje de microbiología experimental en un formato virtual y en contexto de pandemia: una experiencia de implementación de actividades con la utilización de un set portátil en la formación de profesores de Biología y Ciencias Naturales
}

\author{
María José Vargas-Straube ${ }^{1}$ \\ Juan Carlos Gutiérrez Escobar ${ }^{1}$ \\ Javiera Francisca Soto Quiroz ${ }^{1}$ \\ Evelyn Isla Paillamilla ${ }^{1}$ \\ ${ }^{1}$ Universidad Alberto Hurtado (UAH), Chile
}

Resumen. En este trabajo se presenta la implementación de una propuesta didáctica innovadora para realizar actividades prácticas en un curso de microbiología para estudiantes de Pedagogía en Biología y Ciencias Naturales. La propuesta surgió para resolver la necesidad de realizar experiencias prácticas en formato virtual en contexto de pandemia. La metodología consideró el diseño y envío de un set portátil de laboratorio al domicilio de los estudiantes del curso y en la implementación de actividades experimentales asistidas virtualmente por los profesores del curso (una experta en microbiología y un experto en didáctica de las ciencias). Las actividades experimentales incluyeron el cultivo de microorganismos ambientales, la tinción Gram y la elaboración de una investigación personalizada. Los resultados obtenidos durante la implementación de esta secuencia didáctica proceden de la observación del desempeño de los estudiantes durante el trabajo práctico, de la revisión de sus informes y del análisis de una entrevista semiestructurada que se centra en la valoración otorgada por los estudiantes a esta experiencia y su percepción acerca de los aprendizajes logrados.

Palabras clave: microbiología; laboratorio; didáctica; educación científica; educación basada en evidencias; formación inicial docente.

Aprendizagem de microbiologia experimental em formato virtual e no contexto de pandemia: uma experiência de implementação de atividades com o uso de laboratório portátil na formação de professores de Biologia e Ciências Naturais

Resumo. Este trabalho apresenta a implementação de uma proposta didática inovadora para realizar atividades práticas em um curso de microbiologia para estudantes de Licenciatura em Biologia e Ciências Naturais. A proposta surgiu para resolver a necessidade de realizar experiências práticas em formato virtual, no contexto de pandemia. A metodologia considerou a criação e a entrega de um laboratório portátil no domicílio dos alunos e a implementação de atividades experimentais orientadas virtualmente pelos professores do curso (uma especialista em microbiologia e um especialista em didática das ciências). As atividades experimentais incluíram o cultivo de microrganismos ambientais, a coloração de Gram e a elaboração de uma investigação personalizada. Os resultados obtidos durante a implementação desta sequência didática provêm da observação do desempenho dos alunos durante o trabalho prático, da revisão dos seus relatórios e da análise de uma entrevista semiestruturada que enfoca a avaliação dada pelos estudantes a esta experiência e a sua percepção do aprendizado alcançado.

Palavras-chave: microbiologia; laboratório; didática; educação científica; educação baseada em evidências; formação inicial docente.

Learning experimental microbiology in a virtual format in the context of a pandemic: an experience of implementing activities with the use of a portable set in the training of Biology and Natural Sciences teachers.

Abstract. This paper presents the implementation of an innovative didactic proposal to perform practical activities in a microbiology course for students of Pedagogy in Biology and Natural Sciences. The proposal arose to solve the need for practical experiences in virtual format in the context of pandemic. The methodology considered the design and delivery of a portable laboratory set to the homes of the course students and the implementation of experimental activities virtually assisted by the course teachers (an expert in microbiology and an expert in science didactics). The experimental activities included microorganism culture, Gram stain and the elaboration of a personalized investigation. The results obtained during the implementation of this didactic sequence come from the observation of the performance of the students during the practical work, from the review of their reports and the analysis of a semi-structured interview that focuses on the evaluation given by the students to this experience and their perception about the learning achieved.

Keywords: Microbiology; laboratory; didactics; science education; evidence-based education; initial teacher training. 


\section{Introducción}

\subsection{Curso de Microbiología de la carrera de Pedagogía en Biología y Ciencias Naturales}

La carrera de Pedagogía en Biología y Ciencias Naturales de la Universidad Alberto Hurtado, en el sexto semestre de su plan de estudio 2014, dicta un curso de Microbiología que integra la dimensión disciplinar y didáctica, a través del desarrollo de los contenidos científicos específicos de la microbiología y de su enseñanza, lo que se materializa en un trabajo pedagógico articulado entre una doctora en microbiología y un experto en didáctica de las ciencias.

Este curso se ha impartido en modalidad presencial desde el año 2016 hasta el año 2019. Sin embargo, a raíz del contexto de pandemia que se suscitó en Chile y el mundo producto de la infección por SARS-CoV-2, el año 2020 el curso se impartió en modalidad virtual para un grupo de cinco estudiantes de la carrera.

\subsection{Importancia del desarrollo de habilidades científicas en el curso de Microbiología}

La modalidad de trabajo de este curso contempla el desarrollo de clases teóricas y prácticas, las cuales permiten analizar los contenidos disciplinares y abordar algunos de estos mediante experiencias de indagación científica y experimentación en el laboratorio, lo que permite a los futuros profesores construir aprendizajes conceptuales y procedimentales relativos a los distintos tópicos. Las experiencias de investigación en microbiología, en este curso, se estructuran en dos etapas: i) el aprendizaje de técnicas y procedimientos básicos en microbiología experimental y ii) el desarrollo experimental de una pregunta en microbiología.

El aprendizaje de técnicas y procedimientos básicos en microbiología experimental incluye la elaboración de medios de cultivos y soluciones de testeo, el cultivo de microorganismos en medios sólidos y líquidos, la medición del crecimiento bacteriano mediante turbidimetría o conteo de unidades formadoras de colonias (ufc), la realización del procedimiento de tinción Gram, para distinguir entre bacterias Gram-negativas y bacterias Gram-positivas y la visualización de microorganismos mediante microscopía óptica. Esto les permite a los futuros docentes adquirir buenas prácticas de laboratorio, manejar microorganismos en condiciones de asepsia y aprender a utilizar equipos de rutina en microbiología. Por otro lado, el abordaje experimental de una pregunta permite integrar las habilidades experimentales aprendidas en la primera etapa, desarrollar habilidades de pensamiento científico, como el diseño experimental, el análisis de los datos y la interpretación de los resultados y actitudes asociadas al trabajo científico, además, construir conocimiento científico basado en evidencia.

\subsubsection{Importancia de la elaboración de la tinción Gram para la determinación} de la clasificación bacteriana

La tinción Gram es uno de los procedimientos de tinción diferencial más utilizados en microbiología, el cual consiste en una serie de pasos consecutivos de tinción y decoloración de un frotis bacteriano. Este procedimiento permite diferenciar entre bacterias Gram-positivas y Gram-negativas al visualizarlas en el microscopio. El procedimiento de la tinción Gram requiere cuatro pasos básicos que incluyen la aplicación 
de una tinción primaria (cristal violeta) a un frotis fijado con calor, la adición de un mordiente (yodo), una rápida decoloración con una mezcla de alcohol y acetona y, por último, la aplicación de una tinción de contraste (safranina) (Smith y Hussey, 2005). La determinación de la clasificación de bacterias Gram-positivas y Gram-negativas se realiza al visualizar agrupaciones bacterianas de color violeta, no reactivas a la tinción (Gram-positivas), o color rosado, reactivas a la tinción (Gram-negativas).

\subsection{Desarrollo de habilidades y procedimientos experimentales del curso de Microbiología en un formato virtual y en un contexto pandémico}

El re-diseño del curso, para que se pudiera realizar en formato virtual, representó un gran desafío, tanto para el equipo directivo de la carrera como para los docentes del curso, y las grandes preguntas que surgieron tienen relación con la factibilidad de aprender de manera significativa procesos y técnicas experimentales microbiológicas de manera práctica en virtualidad y cómo desarrollar competencias básicas de investigación en estudiantes universitarios.

Para responder a estas preguntas fue necesario presentar propuestas que permitieran promover aprendizajes en torno a los procesos de índole práctica, entendidos como aquellos aprendizajes centrados en el contenido y en los procesos de la ciencia, comprendiendo la utilidad del conocimiento científico en la vida y la sociedad, en concordancia con una visión que dé cuenta de un ciudadano empoderado del conocimiento científico y su contextualización (Sjöström y Eilks, 2018).

La nueva modalidad virtual en la que se han debido impartir las clases en los establecimientos educativos del país desde el año 2020, tanto en la educación escolar como universitaria, ha propiciado la generación de nuevas propuestas de enseñanza que efectivamente promuevan el desarrollo de aprendizajes. En este sentido, y apelando a algunas ideas planteadas por Rivas (2020), no serán los docentes expertos en tecnología los mejor posicionados para rehacer el sistema, serán los conocedores y los apasionados de la didáctica, los que podrán reinventar la enseñanza con sentido y criterio en las condiciones que la realidad les presenta. En el caso de la formación de profesorado de ciencias es aún más crucial, pues los futuros profesores deben aprehender conocimientos relativos a los procesos de la ciencia que requieren de trabajo práctico, pues de lo contrario no serían capaces de realizar una transposición didáctica de los mismos.

A nivel internacional, es reconocida la necesidad de incorporar los trabajos prácticos en la enseñanza de las ciencias, en todos los niveles, utilizando materiales de fácil adquisición y metodologías por indagación que consideren las ideas previas de los estudiantes y promuevan la construcción de contenidos conceptuales y procedimentales, facilitando así el desarrollo de habilidades científicas fundamentales, a través de la transformación de los métodos de enseñanza, lo que además de generar estas habilidades en los estudiantes, permitiría mejorar el desempeño académico y reflexionar sobre la manera en cómo se viene enseñando la ciencia (Sosa y Dávila, 2019; Dyasi, 2014; Carrascosa et al., 2006).

A continuación, se analiza la implementación de actividades con el uso de un set portátil de laboratorio de microbiología asociado a una secuencia didáctica, recuperando de ésta la planificación de las actividades, la progresión de los aprendizajes y 
el proceso de investigación didáctica desde un enfoque epistémico y didáctico (Couso, 2011). La experiencia implicó un diseño de clases con contenidos abordados de manera gradual, actividades guiadas, práctica abundante, mucho diálogo y retroalimentación, entre otras características de la propuesta que dan cuenta de una metodología de enseñanza explícita, coherente con la formación de profesores de ciencias para el siglo XXI (Vásquez-Alonso y Manassero-Mas, 2019). Este set portátil incluyó todos los materiales y reactivos necesarios para la realización de talleres prácticos de microbiología experimental básica. Las indicaciones de utilización de este set fueron entregadas por los docentes del curso en sesiones virtuales sincrónicas.

\section{Materiales y métodos}

\subsection{Elaboración de un set portátil de laboratorio de microbiología}

\subsubsection{Materiales para la elaboración de los sets portátiles del curso}

El equipo de la carrera diseñó y preparó la lista de componentes del set portátil en base a los materiales y reactivos disponibles en el Laboratorio de la carrera. Los materiales consisten en placas Petri, tubos Eppendorf y Falcon, portaobjetos, cubreobjetos, asas bacteriológicas, pinzas metálicas, vasos precipitados, gotarios, cotonitos, papel parafilm, agua destilada, alcohol, guantes, toallas de papel, pisetas y encendedores. Los reactivos líquidos consisten en soluciones de cristal violeta, safranina, alcohol, acetona y lugol. Los reactivos sólidos consisten en medio de cultivo Luria Bertani (LB), glucosa y agar.

Se prepararon cinco sets portátiles, para cada uno de los futuros profesores inscritos en el curso.

\subsubsection{Preparación de las soluciones de los sets portátiles del curso}

El procedimiento de preparación de las soluciones y reactivos que componen el set portátil se muestra en el anexo.

\subsubsection{Componentes del set portátil para cada estudiante y envío a sus domi-} cilios

- 1 tubo Eppendorf con $1 \mathrm{ml}$ de solución de cristal violeta

- 1 tubo Eppendorf con $1 \mathrm{ml}$ de solución de safranina

- 1 tubo Eppendorf con $1 \mathrm{ml}$ de solución de lugol

- 1 tubo Falcon con $50 \mathrm{ml}$ de solución de alcohol-acetona

- 1 bolsa con componentes del medio LB

- 1 bolsa con componentes del medio LB + glucosa

- 2 bolsas con agar

- 10 portaobjetos

- 10 cubreobjetos

- Tiras de papel parafilm

- 5 tubos Eppendorf vacíos y estériles

- 2 tubo2 Falcon de $50 \mathrm{~mL}$ vacíos y estériles

- 5 gotarios

- 5 cotonitos estériles

- 1 botella sellada de $1 \mathrm{~L}$ de agua destilada

- 1 botella sellada de $1 \mathrm{~L}$ de alcohol 
- 1 botella sellada de $1 \mathrm{~L}$ de hipoclorito de sodio

- 4 pares de guantes

- 1 rollo de toalla de papel

- 1 lupa/microscopio digital

- 5 placas Petri de vidrio

- 1 asa bacteriológica en loop

- 1 pinza metálica

- 1 vaso precipitado de $250 \mathrm{~mL}$

- 2 pisetas vacías

- 1 encendedor

Se prepararon 5 cajas con sets portátiles y se enviaron al domicilio de cada estudiante mediante un servicio de encomiendas a domicilio. Se le solicitó a cada estudiante confirmar la correcta recepción del set vía correo electrónico.

\subsection{Protocolos de microbiología realizados con el set portátil}

Los protocolos experimentales realizados por el estudiantado se muestran en el anexo.

\subsection{Monitoreo de las actividades experimentales y la utilización del set portátil}

Mediante sesiones virtuales sincrónicas, se realizaron talleres experimentales con el estudiantado. En cada sesión, los docentes a cargo del curso indicaron, mediante demostraciones o utilizando videos disponibles en páginas web, cómo realizar los protocolos con buenas prácticas de laboratorio y observaron, mediante cámara web, la ejecución de estos protocolos por parte de los estudiantes. Las sesiones fueron dinámicas, dialógicas y con retroalimentación constante entre docentes y estudiantes, con el objetivo de que estos últimos pudiesen resolver sus dudas, integrar las indicaciones obtenidas por cámara web y poder realizar estas indicaciones en sus hogares bajo la observación y asistencia sincrónica. Además, los docentes dieron indicaciones específicas para que los estudiantes pudiesen realizar el registro de sus resultados durante las sesiones asincrónicas.

\section{Sesión 1: Elaboración de medios de cultivo en placas Petri}

Primero se indicó a los estudiantes las instrucciones para la realización de los protocolos de preparación de pisetas con agua destilada y con etanol 75\%. Luego se les señalaron indicaron las instrucciones para la realización del protocolo de preparación de placas Petri con medio de cultivo LB-glucosa-agar. Los estudiantes almacenaron sus placas de cultivo estériles en el refrigerador hasta la tercera sesión.

\section{Sesión 2: Calibración del microscopio}

Su utilizó una lupa microscopio digital de uso casero con conexión USB para computador, presentando las siguientes características de utilización doméstica: aumento de hasta 1000x digitales, resolución de campo de 640 × 480 píxeles, enfoque de un rango de 15 a 40 mm y conexión directa con sistemas Android. 
Durante la sesión, la utilización del microscopio fue mediada por un proceso de exploración libre que permitiera a los estudiantes explorar elementos cotidianos de tal forma que comprendieran su funcionamiento y en especial la técnica de enfoque del microscopio, y adicionalmente pudiesen establecer referencias de escala para los diferentes objetos.

\section{Sesión 3: Toma de muestras e inoculación en placas de cultivo}

Se les indicaron a los estudiantes las instrucciones para la realización del protocolo de muestreo e inoculación de microorganismos utilizando las placas de cultivo preparadas en la primera sesión.

Sesión 4: Elaboración de la tinción Gram para la clasificación bacteriana y visualización al microscopio

Se les indicaron a los estudiantes las instrucciones para la realización del protocolo de la técnica de tinción Gram de las bacterias obtenidas en la tercera sesión. Una vez obtenidos los frotis teñidos, se visualizaron al microscopio hasta obtener registros fotográficos de lo observado.

Sesión 5: Desarrollo de una pregunta individual de indagación en microbiología

Se trabajó con cada estudiante, de forma individual y sincrónica, para que elaborara una pregunta de indagación en microbiología. Se asistió a cada estudiante para que su pregunta cumpliera con dos requisitos obligatorios: abordar uno o más contenidos disciplinares entregados en el curso de microbiología y poseer la potencialidad de ser respondidas mediante un diseño experimental simple que implicara la utilización del set portátil de laboratorio.

Sesión 6: Elaboración de un diseño experimental en torno a una pregunta individual de indagación en microbiología

Se trabajó con cada estudiante, de forma individual y sincrónica, para que elaborara un diseño experimental que respondiese su pregunta en microbiología utilizando el set portátil de laboratorio. Se asistió a cada estudiante para que su diseño fuera ordenado y presentara una secuencia metodológica sencilla.

\subsection{Indicaciones del formato de reporte de los resultados obtenidos en los experimentos de microbiología}

Se les indicó a los estudiantes, mediante correo electrónico, la siguiente pauta de informe para el reporte de sus resultados experimentales.

1. Introducción: Marco teórico, hipótesis, objetivo general, objetivos específicos.

2. Materiales y métodos: Lista de materiales y procedimiento experimental.

3. Resultados: Descripción de resultados obtenidos. Incorporar registro fotográfico, tablas y gráficos en caso de ser necesario.

4. Discusión

5. Conclusiones

6. Bibliografía 


\subsection{Entrevistas semi-estructuradas a los estudiantes para recoger} sus experiencias como usuarios de un set portátil de laboratorio

Finalizada la experiencia, el equipo de la carrera elaboró una entrevista para los estudiantes, con el objetivo de recoger información acerca de la utilización del set portátil entregado y las actividades experimentales realizadas con éste. Esta entrevista se realizó de forma oral a cada estudiante, por separado. A continuación, se muestra la entrevista realizada.

En el marco de la contingencia sanitaria que estamos viviendo desde marzo de 2020 debimos adaptar los procesos de enseñanza-aprendizaje de todas las actividades curriculares para realizarlas en modalidad virtual. Uno de los principales desafíos se presentó en aquellos cursos que tienen una componente práctica, entre ellos el curso de Microbiología. En este sentido, quisiéramos conocer tus apreciaciones respecto a la experiencia vivida, a propósito del trabajo realizado con el uso de un kit de materiales que fue enviado a tu domicilio, para abordar las actividades prácticas guiadas por los docentes a cargo del curso. Te realizaremos siete preguntas.

1. ¿Quéte pareció la iniciativa de enviar un set portátil de materiales para abordar la componente práctica de este curso? ¿Qué aspectos de esta experiencia consideras valiosos para tu formación disciplinar y didáctica? ¿Por qué?

2. ¿En qué medida consideras que pudiste desarrollar aprendizajes conceptuales, habilidades y actitudes científicas a través de esta experiencia?

3. ¿Podrías dar cuenta de alguna habilidad de pensamiento científico o procesos de la ciencia que pudieras haber identificado?

4. ¿Consideras que pudiste desarrollar algunas actitudes científicas en este trabajo que realizaste?

5. 5. ¿Crees que habrías logrado estos aprendizajes que señalas sin contar con el set portátil de materiales? ¿Por qué?

6. ¿Qué elementos del trabajo práctico con estos sets portátiles mejorarías, ya sea en términos de materiales, adaptaciones a la forma de trabajo, sesiones sincrónicas y asincrónicas? ¿ Existe algún otro tema en cuanto a materiales u otro tipo de adaptaciones que consideras sería pertinente realizar?

7. Después de todos estos análisis y proyectando tu futuro quehacer como profesor ¿Realizarías esta experiencia con estudiantes en el aula, tal como te fue presentada? ¿Por qué? Si consideras que habría que introducir ajustes ¿Cuáles serían?"

\section{Resultados}

3.1 Cultivo de bacterias ambientales y determinación de su clasificación por tinción Gram

\subsubsection{Cultivo de microorganismos}

Cada estudiante del curso tomó muestras de diferentes superficies de su hogar y las cultivó en placas Petri con medio LB-glucosa hasta observar crecimiento de colonias de microorganismos con diferentes características visuales (Tabla 1, Fig. S1). 
Tabla 1. Lugares del hogar donde cada estudiante tomó muestras para cultivar microorganismos.

\begin{tabular}{ccccc}
\hline Estudiante & Muestra 1 & Tiempo de cultivo & Muestra 2 & Tiempo de cultivo \\
C. A. & Suela de zapatilla & No especificó & Superficie del celular & No especificó \\
F. A. & Saliva humana & No especificó & --- & --- \\
R. G. & Saliva de perro & No especificó & $\begin{array}{c}\text { Superficie de naranjas } \\
\text { de jardín }\end{array}$ & No especificó \\
R.P. & Saliva de perro & 5 días & $\begin{array}{c}\text { Agua estancada de } \\
\text { jardín }\end{array}$ & 5 días \\
F. V. & Saliva de gato & No especificó & --- & ---
\end{tabular}

No tomó muestra.

\subsubsection{Determinación de la clasificación bacteriana mediante tinción Gram y observación al microscopio}

Luego de obtener colonias bacterianas, los estudiantes realizaron frotis bacterianos sobre portaobjetos y los tiñeron con tinción Gram. En la Figura S2 se muestran frotis teñidos provenientes de muestras de saliva de perro (Fig. S2A) y de muestras de suela de zapatilla (Fig. S2B). Para determinar si las bacterias obtenidas correspondían a bacterias Gram-positivas o bacterias Gram-negativas, los estudiantes analizaron los frotis bacterianos teñidos, en una lupa/microscopio digital (Fig. 1). En los resultados de dos estudiantes se observan imágenes con agrupamientos bacterianos de color rosado (negativos a la tinción) (Fig. 1A) y de color violeta (positivos a la tinción) (Fig. 1B). Según estos resultados las bacterias de la muestra proveniente de saliva de perro (tomada por el estudiante R. G.), se clasificarían como bacterias Gram-negativas (Fig. 1A) y las bacterias de la muestra proveniente de suela de zapatilla (tomada por la estudiante C. A.), se clasificarían como bacterias Gram-positivas (Fig. 1B). Debido al límite de resolución del microscopio, no fue posible amplificar las imágenes de los frotis para observar la morfología celular de las bacterias de esas agrupaciones.

Figura 1. Fotografías de frotis bacterianos teñidos con tinción Gram, obtenidas con lupa/ microscopio digital.

A

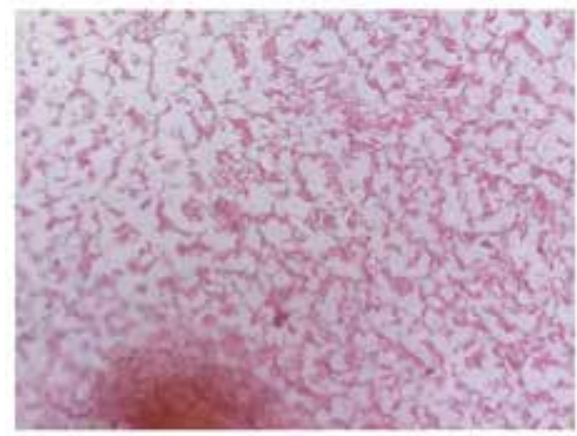

B

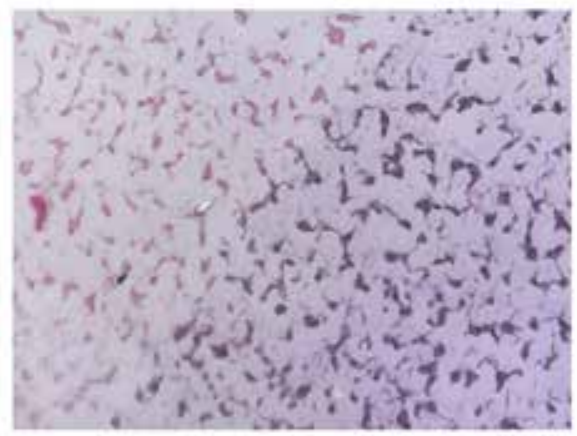

A. Fotografía de bacterias provenientes de saliva de perro (estudiante R. G.). B. Fotografía de bacterias provenientes de suela de zapatilla (estudiante C. A.).

Fuente: Archivo de los autores. 


\subsection{Desarrollo de una investigación experimental con el set portátil para responder una pregunta individual en microbiología}

Tres estudiantes del curso realizaron una pregunta individual en microbiología y la respondieron mediante un diseño experimental utilizando el set portátil de laboratorio. A continuación, se resumen los aspectos importantes del informe de cada estudiante.

\subsubsection{Diseño experimental y resultados de la investigación del estudiante R. G.}

Pregunta de indagación en microbiología:

¿Cuál es el rango óptimo de temperatura de crecimiento de bacterias aisladas desde la superficie del fruto de un árbol de naranjas?

Origen de la pregunta:

El estudiante previamente había aislado bacterias desde la superficie de naranjas de un árbol de su jardín (Tabla 1) y las había cultivado en medio LB-glucosa durante 3 días a temperatura ambiente (temperatura alrededor de $18^{\circ} \mathrm{C}$ ). Sin embargo, al almacenarlas en el refrigerador, observó que, al cabo de 5 días, habían crecido más colonias bacterianas que a temperatura ambiente. En base a su observación, se preguntó si las bacterias que aisló podrían crecer a diferentes temperaturas, y cuál sería el rango óptimo de temperatura de crecimiento.

Diseño experimental:

Crecimiento de bacterias presentes en la superficie de una naranja en tres lugares del hogar con diferente temperatura ambiente y determinación del rango óptimo de temperatura de crecimiento.

Secuencia metodológica del experimento:

1. Toma de muestras provenientes de la superficie de un fruto de árbol de naranjas de jardín e inoculación en tres placas Petri con medio LB-glucosa.

2. Depósito de las placas diferentes lugares del hogar durante tres días: jardín (condición 1), refrigerador (condición 2) y estante (condición 3).

3. Registro de la temperatura de cada uno de los tres lugares del hogar a las $7,11,15,19$ y 23 horas de los días 1 al 3.

4. Registro visual de la presencia o ausencia de colonias bacterianas en los días 1 y 3 . Conteo del número de colonias.

5. Depósito de las tres placas, crecidas durante tres días en diferentes lugares, en el estante de la condición 2 durante dos días más.

6. Registro visual de la presencia o ausencia de colonias bacterianas en el día 5. Conteo del número de colonias.

Resultados y conclusiones experimentales:

Las bacterias provenientes de la superficie de un fruto de un árbol de naranjas crecieron a diferentes temperaturas, entre 12 y $31^{\circ} \mathrm{C}$ (condición 1 , jardín), alcanzando un mayor crecimiento a temperaturas constantes entre 18 y $20^{\circ} \mathrm{C}$ (condición 3 , estante) e inhibiendo su crecimiento a temperaturas constantes entre 10 y $12^{\circ} \mathrm{C}$ (condición 2 , refrigerador) (Fig. S3). 
3.2.2 Diseño experimental y resultados de la investigación del estudiante $R$. P.

Pregunta de indagación en microbiología:

¿Qué concentración de aceite esencial de jengibre inhibe el crecimiento de bacterias provenientes de la cavidad bucal de un humano adulto?

Origen de la pregunta:

El estudiante realizó una investigación bibliográfica sobre las propiedades antibacterianas de los componentes del jengibre y se preguntó si éste tendría efecto antibacteriano contra las bacterias patógenas que producen las caries dentales.

Diseño experimental:

Preparación de aceite esencial de jengibre y aplicación sobre una placa inoculada con muestra de cavidad de humano adulto, para la determinación de la inhibición del crecimiento bacteriano.

Secuencia metodológica del experimento:

1. Preparación de aceite de jengibre (Zingiber officinale) mediante un hidrodestilador casero.

2. Preparación de diferentes concentraciones de una solución de aceite esencial jengibre: soluciones al 100,75 y $25 \% \mathrm{p} / \mathrm{v}$.

3. Toma de muestras provenientes de la cavidad oral de un humano adulto e inoculación en tres placas Petri con medio LB-glucosa.

4. Aplicación de discos de papel, embebidos con las tres soluciones de aceite esencial, sobre tres placas diferentes: una placa control sin inóculo y dos placas inoculadas con la muestra.

5. Incubación de las placas durante 4 días.

6. Registro visual de las placas para la observación de halos de inhibición del crecimiento bacteriano alrededor de los discos embebidos con aceite esencial.

Resultados y conclusiones experimentales:

No se observó crecimiento bacteriano en las placas inoculadas, a excepción de una placa en la que se observó crecimiento sobre un disco de papel embebido en solución de aceite esencial al 25\%. El estudiante concluyó que el disco podría haber estado contaminado por manipulación experimental y propuso que en una próxima implementación se podría tomar muestra bacteriana desde esa contaminación, que es capaz de crecer en las condiciones testeadas (Fig. S4).

3.2.3 Diseño experimental y resultados de la investigación del estudiante F. V.

Pregunta de indagación en microbiología:

¿El hipoclorito de sodio y el alcohol poseen la misma capacidad antiséptica al aplicarlos sobre la superficie de un mesón?

Origen de la pregunta:

Ante la utilización cotidiana de ambos productos antisépticos, el estudiante realizó una investigación bibliográfica sobre las propiedades químicas y el efecto antibacteriano de cada producto. Luego de esto se preguntó si tendrían diferente efecto antibacteriano, o no, al aplicarlos sobre la superficie de un mesón. 
Diseño experimental:

Toma de muestra de la superficie de un mesón aseado con una solución de hipoclorito de sodio o con una solución de alcohol, por separado, inoculación en placas de cultivo y comparación del crecimiento bacteriano.

Secuencia metodológica del experimento:

1. Aplicación de hipoclorito de sodio $10 \% \mathrm{p} / \mathrm{v}$ sobre la mitad de la superficie de un mesón desaseado y toma de muestra para la inoculación en una placa Petri con medio LB-glucosa.

2. Aplicación de alcohol $75 \% \mathrm{p} / \mathrm{v}$ sobre la otra mitad de la superficie del mesón y toma de muestra para la inoculación en una placa de Petri con medio LB-glucosa.

3. Incubación de las dos placas inoculadas durante 3 días, en conjunto con una placa no inoculada.

4. Registro visual de las placas para la observación de crecimiento bacteriano.

Resultados y conclusiones experimentales:

Las tres placas testeadas presentaron contaminación ambiental, por lo que no fue posible obtener conclusiones con respecto a la eficacia de cada producto antiséptico (Fig. S5).

\subsection{Análisis de la propuesta de implementación del set mediante una entrevista}

Se realizó una entrevista semi-estructurada a cada estudiante, para recoger su percepción acerca de la implementación de actividades experimentales utilizando el set portátil.

En general, los estudiantes valoraron positivamente la iniciativa de recibir este set en sus hogares, sobre todo en el contexto de cuarentena estricta que se vivió el año 2020 en el país. El solo hecho de enviar estos sets tuvo un impacto positivo a nivel emocional y con ello en la predisposición de los estudiantes hacia el desarrollo de las actividades prácticas. Se mencionan algunas citas de estudiantes: "Se preocuparon de que nosotros pudiéramos aprender lo mejor posible", "Considero que fue una súper buena decisión, que no fuera teórico", "Desde el componente emocional fue muy positiva".

Entre los aspectos valiosos de la experiencia para la formación disciplinar, los estudiantes destacaron la validación de algunos contenidos de microbiología aprendidos de forma teórica durante el curso, como, por ejemplo, las técnicas de crecimiento microbiano y los fundamentos de la tinción Gram. Se mencionan las siguientes citas de algunos estudiantes: "Aprendí a manejar técnicas de laboratorio", "Nos permite acercarnos a través de los sentidos".

Sin embargo, los estudiantes destacaron con mayor énfasis que la experiencia les permitió desarrollar su formación didáctica. Entre estos aspectos destacaron la factibilidad de poder hacer ciencia en sus hogares, realizando protocolos sencillos y creativos y evidenciando empíricamente aplicaciones de la microbiología en la vida cotidiana. Se mencionan algunas citas de estudiantes: "En términos más didácticos, dar la oportunidad a estudiantes de poder hacer estos procedimientos en su casa, 
sin necesidad de tener un laboratorio, aunque sean materiales de laboratorio, da una sensación de cercanía, de factibilidad, de accesibilidad a los procesos para construir saberes, y que no es necesario estar en un laboratorio o ir presencial a la universidad para poder desarrollar estos mismos procesos",, "Intencionar que los aprendizajes se den de una manera contextual, o sea que las personas puedan encontrar en su vida cotidiana cosas relacionadas con la ciencia".

Además, los estudiantes valoraron considerablemente la experiencia de haber realizado un diseño experimental para responder sus preguntas, utilizando un set portátil sencillo y materiales cotidianos disponibles en sus hogares. Esto último lo destacaron como futuros profesores debido la factibilidad de poder proyectar esta experiencia en aulas escolares e impulsar el aprendizaje práctico con pocos recursos. Se menciona la siguiente cita de un estudiante: "Poder trabajar con pocos materiales, con pocos recursos, creo que es totalmente viable para poder acercarnos al aula en variados niveles. En tercero y cuarto medio se analizan temáticas de salud asociadas a ciertos patógenos, entonces creo que es totalmente factible de desarrollar esto en el colegio, no veo limitaciones. De hecho, lo único que veo son posibilidades de hacerlo, diversas posibilidades de hacerlo".

Cabe destacar que la experiencia de haber diseñado una metodología experimental para responder sus preguntas también fue valorada en términos de que les permitió desarrollar habilidades y actitudes asociadas al trabajo científico. Entre las cuales mencionaron la observación de fenómenos, el desarrollo de la curiosidad y la creatividad, la elaboración de hipótesis y predicción de resultados, el diseño de metodologías experimentales, el trabajo sistemático y riguroso, el registro de datos, la resolución de problemáticas, la interpretación de resultados y la formulación de conclusiones. Se menciona la siguiente cita de un estudiante: "Siento que uno si se ordena, puede hacer las cosas bien, aunque sea algo muy sencillo, y eso sencillo no le quita valor científico a lo que uno está haciendo, que también es enriquecedor para uno como experimentador".

Entre las mejoras que los estudiantes sugieren a los componentes del set portátil, mencionaron la disposición de un microscopio con mayor resolución, ya que el que se les envió no les permitió amplificar las imágenes de sus muestras bacterianas para poder observar la forma celular de éstas. Entre las mejoras que los estudiantes sugieren a las indicaciones de las actividades experimentales, mencionaron la disposición de cápsulas informativas previas a las sesiones experimentales sincrónicas, con el objetivo de poder revisar, previo a la clase, las indicaciones y procedimientos. Esto da cuenta de un trabajo metacognitivo por parte de los estudiantes y de la búsqueda de mejora de los procesos de enseñanza en función de los aprendizajes.

Finalmente, los estudiantes declararon que el set portátil de materiales contribuyó efectivamente a los aprendizajes propuestos, considerando que fue esencial para la motivación y el abordaje práctico del curso. Se menciona la siguiente cita de un estudiante: "Es súper difícil no maravillarse con el mundo microscópico y eso fue gracias al set, o sea el set es lo que nos acercó un poco a esta situación de poder encantarnos y poder adquirir esos aprendizajes". 


\subsection{Análisis didáctico-pedagógico de la experiencia de implementación del set portátil}

Los estudiantes R.G., R.P. y F. V. realizaron diseños experimentales coherentes con sus preguntas individuales, los cuales consideraron el material disponible en el set portátil, las técnicas de medición de crecimiento bacteriano enseñadas en los contenidos disciplinares del curso de Microbiología y propuestas de protocolos sencillos, ordenados y metódicos. Con esta experiencia los estudiantes integraron los contenidos disciplinares abordados en su investigación y desarrollaron habilidades de pensamiento científico, como la observación de fenómenos, elaboración de hipótesis, diseño y ejecución de protocolos experimentales, registro de datos y elaboración de conclusiones. Se destacan los diseños experimentales de los estudiantes R. G. y R. P., por su creatividad en responder la pregunta indagatoria con elementos de su hogar adicionales a los del set portátil enviado. En la investigación de R. G. se incluyó la medición periódica de la temperatura ambiental con un termómetro del cual disponía el estudiante. En la investigación de R. P. se incluyó la elaboración de aceite esencial de jengibre mediante un hidrodestilador casero diseñado por el estudiante. La introducción al diseño experimental de elementos adicionales disponibles en sus hogares da cuenta del interés que despertó en estos estudiantes la oportunidad de responder experimentalmente, y de forma asequible, una pregunta indagatoria de interés personal.

La Naturaleza de la Ciencia $(\mathrm{NdC})$ se vuelve un factor fundamental para la comprensión del quehacer de la ciencia, y por cierto de esta experiencia; Cofré (2012) expone diez puntos denominados "elementos de consenso", los cuales sugieren que se hagan patentes para el aprendizaje profundo de los estudiantes, de manera parcelada, uno a uno. En este caso se priorizaron dos puntos del consenso antes mencionado: i) La ciencia incluye la creatividad y la imaginación en todas las etapas de la investigación; ii) El conocimiento científico es provisorio o tentativo, las posiciones científicas cambian cuando se obtiene nueva evidencia o cuando la evidencia anterior es reinterpretada por los científicos.

Desde el ejercicio intencionado en la implementación de un set portátil de laboratorio de Microbiología, el estudiantado de este curso comprendió y puso en práctica estos dos elementos, dejando que la imaginación y la creatividad los llevara a la reinterpretación de los experimentos propuestos, incluyendo variables nuevas, elementos adicionales para la experimentación, revisando información de otros experimentos y reinterpretándolos o descartándolos con el fin de expandir sus conocimientos desde la autonomía. A modo de ejemplo, se menciona la necesidad del estudiantado de expandir las muestras ambientales tomadas desde sus hogares a sus barrios, el cuestionamiento y la realización de nuevos diseños experimentales cuando los resultados esperados no ocurrieron, la fabricación de aceite esencial de jengibre para entender su potencial bactericida y el estudio de protocolos adicionales que les permitieran mejorar sus prácticas.

Respecto al desarrollo de habilidades científicas, durante las actividades de implementación del set portátil se intencionaron: la formulación de preguntas, observación, descripción y registro de datos, ordenamiento e interpretación de datos, 
elaboración y análisis de hipótesis, productos y explicaciones y discusión ética. Las habilidades antes mencionadas se basan en los requerimientos expresados por el Ministerio de Educación de Chile para los estándares iniciales de formación docente.

\section{Discusión}

\subsection{Implementación de un set portátil de laboratorio e indicación de las actividades experimentales en un formato virtual}

La adquisición de conocimientos prácticos de microbiología experimental, por parte de futuros profesores de biología y ciencias naturales, es fundamental para su formación. La microbiología es una rama de las ciencias naturales que contribuye al Currículo Nacional desde la perspectiva de dar fundamentos a temáticas integradas que deben aprender los estudiantes de algunos cursos de educación básica y media: $7^{0}$ básico, infecciones de transmisión sexual, barreras defensivas y rol de los microorganismos; $8^{\circ}$ básico, absorción de nutrientes tanto en plantas como humanos; $1^{\circ}$ medio, evidencia taxonómica, evolutiva y rol de los microorganismos en los ecosistemas; y $2^{\circ}$ medio, uso biotecnológico de microorganismos (Ministerio de Educación de Chile, 2019).

La realización de clases en formato virtual en contexto de pandemia dificulta desarrollar conocimientos prácticos, sobre todo, aprendizajes procedimentales en el laboratorio en un curso de microbiología. En ese contexto, la implementación de una secuencia didáctica que considera el uso de un set portátil de laboratorio desde los hogares de los estudiantes y la descripción de los procedimientos básicos de microbiología experimental en un formato virtual fue una propuesta que abordó esta necesidad. Tanto el equipo de la carrera, como sus estudiantes, evaluaron el proceso como una experiencia exitosa de adaptación de la docencia en contexto de crisis. Los informes realizados por los estudiantes y los resultados de las entrevistas dan cuenta de que la experiencia les permitió a éstos integrar contenidos disciplinares del curso de Microbiología, tales como "clasificación bacteriana según tinción Gram" y "crecimiento bacteriano" de forma dinámica y experiencial. Al comparar la experiencia de un laboratorio de docencia realizado en un formato virtual, con la de un laboratorio de docencia realizado de forma presencial, como se había realizado en años anteriores, se aprecia que los estudiantes se involucraron mucho más en la correcta elaboración de sus experimentos, ya que fueron monitoreados y asistidos de forma individual en todo el proceso experimental mediante sesiones virtuales. Además, el diseño y ejecución de protocolos experimentales por parte de los estudiantes, con materiales y procedimientos sencillos otorgados por el set portátil, les permitió proyectarse experimentalmente de forma plausible en el aula escolar nacional. Esta capacidad es valorable para un profesor en formación de Biología y Ciencias Naturales.

Cabe destacar que, aunque el proceso fue efectivo en términos del desarrollo de contenidos prácticos fundamentales del curso, existen algunos aspectos, propios de la portabilidad, que se pueden mejorar. Uno de estos aspectos es modificar el microscopio portátil que se dispuso, pues se envió una lupa digital portátil de uso didáctico, cuyas indicaciones del fabricante informan un aumento de hasta 1000X, sin embargo, en las sesiones prácticas realizadas, no fue posible utilizar el microscopio en una amplificación tal que permitiese observar la forma celular de las bacterias analizadas (Fig. 1). Para efectos de la sesión práctica de tinción Gram realizada, los estudiantes 
lograron distinguir agrupaciones bacterianas de color violeta o color rosa, lo cual les permitió clasificarlas según su reactividad a la tinción, sin embargo, algunas muestras no pudieron ser analizadas utilizando este microscopio. Se recomienda disponer otro tipo de microscopio portátil en una segunda versión de implementación de este set. Una alternativa más conveniente para los propósitos del curso podría ser la utilización del microscopio de origami Foldscope, el cual es un microscopio óptico de bajo costo y validado en ciencia y educación (Cybulski et al. 2014).

\subsection{Promoción de propuestas didácticas para la enseñanza de la microbiología}

Últimamente se ha abordado la necesidad de cambiar la forma en que se imparten los cursos de ciencias en la educación superior, con el objetivo de que los estudiantes comprendan de forma más profunda e integradora los conceptos fundamentales y desarrollen las habilidades científicas necesarias para abordar futuros retos y problemáticas. En la rama de la enseñanza de la microbiología, las nuevas herramientas didácticas han incluido la utilización de plataformas interactivas, redes sociales y metodologías de construcción de conocimiento basado en evidencias científicas (Merkel 2016).

En ese contexto, la propuesta de nuestro equipo, de implementar laboratorios portátiles virtuales para la enseñanza de conocimientos prácticos a estudiantes de microbiología, es una herramienta didáctica novedosa y factible. El set utilizado por los estudiantes les permitió desarrollar, mediante una investigación experimental, una pregunta personalizada en microbiología, y, de esta forma, integrar el conocimiento conceptual de determinados tópicos en base a su curiosidad individual y a los resultados que obtuvieron en sus experimentos. Esta es una herramienta didáctica que, por su sencillez metodológica, incluso se podría proyectar su uso en aulas escolares.

Cabe destacar que la enseñanza de la microbiología en aulas escolares mediante herramientas didácticas innovadoras se ha abordado en diferentes países de Latinoamérica. Se mencionan, a modo de ejemplo, un caso de Chile, con la implementación de laboratorios portátiles de microbiología y biología molecular en formato presencial (https://laboratoriosportatiles.cl/), y un caso de Uruguay, con la propuesta de la utilización de cómics para la enseñanza de la microbiología (Morel et al. 2019; Scavone et al. 2019).

\section{Conclusión}

El aprendizaje de microbiología experimental en un formato virtual en contexto de pandemia, por parte de futuros profesores y profesoras de Biología y Ciencias Naturales, fue posible debido a la implementación sistemática de un set portátil, enviado al domicilio de cada estudiante, y a la asistencia virtual sincrónica de los profesores del curso de microbiología para la indicación de las actividades experimentales.

La experiencia de implementación fue exitosa en términos de los objetivos pedagógicos logrados: i) integración por parte de los estudiantes de conocimientos disciplinares y conceptos específicos impartidos durante las sesiones teóricas del curso de microbiología, ii) adquisición de habilidades y actitudes de pensamiento y 
trabajo científico durante la realización de las sesiones prácticas de laboratorio de microbiología experimental, y iii) un trabajo intencionado de elementos relativos a Naturaleza de las Ciencias.

El éxito de esta experiencia le permitió al equipo docente de la carrera reiterar la implementación de sesiones virtuales de laboratorio de microbiología mediante un set portátil para los estudiantes del año académico 2021 y replicar el envío de sets portátiles de laboratorio al domicilio de estudiantes de otros cursos de la carrera.

El aprendizaje adquirido por los docentes a cargo de la actividad curricular servirá para plantear propuestas de mejora cuando se retome el trabajo presencial en la Universidad.

\section{Agradecimientos}

Se agradece a los estudiantes de este curso de microbiología, por su constante motivación para llevar a cabo esta propuesta de implementación de actividades experimentales con la utilización de un set portátil en un formato virtual, y por su consentimiento para la publicación de sus resultados experimentales.

\section{Bibliografía}

Carrascosa, J., Gil-Pérez, D. y Vilches, A. (2006). Papel de la actividad experimental en la educación científica. Cad. Brás. Ens. Fis., 23(2), 157-181. https://doi.org/10.5007/\%25x.

Cofré, H. (2012). La enseñanza de la naturaleza de la ciencia en Chile: del currículo a la sala de clases. Revista Chilena de Educación Científica, 11 (1), 12-21. Recuperado de https:// bit.ly/3yQ3j29.

Couso, D. (2011). Las secuencias didácticas en la enseñanza y el aprendizaje de las ciencias: modelos para su diseño y validación. En Caamaño, A. (coord.), Didáctica de la física y química. Barcelona: Graó.

Cybulski J., Clements, J. y Prakash, M. (2014). Foldscope: origami-based paper microscope. PLoS ONE. 9(6). https://doi.org/10.1371/journal.pone.0098781.

Dyasi, H. (2014). Enseñanza de la ciencia basada en la indagación: razones por las que debe ser la piedra angular de la enseñanza y aprendizaje de la ciencia. En Dyasi, H., Harlen, W., Figueroa, M., Léna, P., y López, P. La Enseñanza de la Ciencia en la Educación Básica. Antología sobre Indagación. (pp. 9-18). México: Innovec. Recuperado de https:// bit.ly/3yPlyoo

Merkel, S. (2016). American Society for Microbiology resources in support of an evidence-based approach to teaching microbiology. FEMS Microbiol Lett, 363(16). https://doi.org/10.1093/ femsle/fnw172.

Ministerio de Educación de Chile (2019). Progresión de objetivos de aprendizaje para Ciencias Naturales de $7^{\circ}$ Básico a $2^{\circ}$ Medio. Recuperado de https://bit.ly/3AMoibr.

Morel, M., Peruzzo, N., Juele, A. y Amarelle, V. (2019). Comics as an educational resource to teach microbiology in the classroom. Journal Microbiology \& Biology Education, 20(1). https:// doi.org/10.1128/jmbe.v20i1.1681.

Rivas, A. (2020). Pedagogía de la excepción ¿cómo educar en la pandemia? Universidad de San Andrés. Recuperado de https://bit.ly/3yPyB9a.

Scavone, P., Carrasco, V., Umpiérrez, A., Morel, M., Arredondo, D y Amarelle, V. (2019). Microbiology can be comic. FEMS Microbiol Lett, 366(14). https://doi.org/10.1093/femsle/fnz171. 
Sjöström, J. y Eilks, I. (2018). Reconsidering different visions of scientific literacy and science education based on the concept of bildung. En Y. J. Dori, Z. Mevareach, y D. Bake (Eds.), Cognition, metacognition and culture in STEM education (pp. 65-88). Dordrecht: Springer. https:// doi.org/10.1007/978-3-319-66659-4_4.

Smith, A. y Hussey, M. (2005). Gram stain protocols. American Society for Microbiology. Washington Recuperado de https://bit.ly/3APnkGH.

Sosa, J. y Dávila, D. (2019). La enseñanza por indagación en el desarrollo de habilidades científicas. Educación y Ciencia, 23, 605-624. Recuperado de https://bit.ly/3xUnSZH.

Vásquez-Alonso, A. y Manassero-Mas, M. (2019). La educación de ciencias en contexto: Aportaciones a la formación del profesorado. Tecné, Episteme y Didaxis: TED, 46, 15-37. https://doi. org/10.17227/ted.num46-10538. 


\section{Anexo}

\subsection{Materiales y métodos}

\subsubsection{Preparación de las soluciones de los sets portátiles del curso}

Se prepararon las siguientes soluciones y reactivos que componen el set portátil:

- Cristal violeta: Se prepararon $100 \mathrm{~mL}$ de una solución de cristal violeta al $2 \%$ ( $p / v)$ en agua. Se prepararon alícuotas de $1 \mathrm{~mL}$ de esta solución en tubos Eppendorf, considerando un tubo para cada set.

- Safranina 1\% (p/v): Se prepararon $100 \mathrm{~mL}$ de una solución de safranina al 1\% (p/v) en agua. Se prepararon alícuotas de $1 \mathrm{~mL}$ de esta solución en tubos Eppendorf, considerando un tubo para cada set.

- Alcohol-acetona: Se prepararon $500 \mathrm{~mL}$ de una solución alcohol-acetona ( $75 \% \mathrm{v} / \mathrm{v}$ de alcohol y $25 \% \mathrm{v} / \mathrm{v}$ de acetona). Se prepararon alícuotas de 50 $\mathrm{mL}$ de esta solución en tubos Falcon, considerando un tubo para cada set.

- Medio de cultivo LB: Se prepararon los componentes del medio LB equivalentes a una solución final del $100 \mathrm{~mL}$. Para esto se añadieron 0,5 g de cloruro de sodio, $0,5 \mathrm{~g}$ de extracto de levadura y $1 \mathrm{~g}$ de peptona de caseína en una bolsa plástica. Se preparó una bolsa para cada set.

- Medio de cultivo LB-glucosa: Se prepararon los componentes del medio LB equivalentes a una solución final del $100 \mathrm{~mL}$. Para esto se añadieron 0,5 g de cloruro de sodio, 0,5 g de extracto de levadura, 1 g de peptona de caseína y $1 \mathrm{~g}$ de glucosa en una bolsa plástica. Se preparó una bolsa para cada set.

- Agar: Se masaron 1,5 g del reactivo agar, equivalentes a una solución de $100 \mathrm{~mL}$ y se depositaron en una bolsa plástica. Se prepararon dos bolsas para cada set.

\subsubsection{Protocolos de microbiología realizados con el set portátil}

Se proporcionaron los siguientes protocolos, que fueron enviados mediante correo electrónico y socializados posteriormente.

Protocolo de preparación de piseta con agua destilada

1. Depositar $400 \mathrm{~mL}$ de agua destilada en una piseta vacía. Medir ese volumen con un tubo Falcon de $50 \mathrm{~mL}$ estéril.

2. Mantener la piseta cerrada a temperatura ambiente.

Protocolo de preparación de piseta con etanol $75 \%$

1. Depositar $100 \mathrm{~mL}$ de agua destilada en una piseta vacía. Medir ese volumen con un tubo Falcon de $50 \mathrm{~mL}$ estéril.

2. Depositar $300 \mathrm{~mL}$ de etanol en la misma piseta. Medir ese volumen con el mismo tubo Falcon de $50 \mathrm{~mL}$.

3. Mantener la piseta cerrada a temperatura ambiente. 
Protocolo de preparación de placas Petri con medio de cultivo LB-glucosa-agar

1. Depositar $100 \mathrm{~mL}$ de agua destilada en una olla limpia. Medir ese volumen con un tubo Falcon de $50 \mathrm{~mL}$ estéril.

2. Verter todo el contenido de la bolsa plástica con medio LB-glucosa en la olla.

3. Verter todo el contenido de una bolsa plástica con agar en la olla.

4. Revolver la olla con una cuchara limpia.

5. Calentar la olla a baño María hasta lograr una consistencia homogénea y nítida de la solución del medio LB-glucosa-agar.

6. Enfriar la olla tapada durante 1 minuto.

7. Verter $20 \mathrm{~mL}$ de medio LB-glucosa-agar en una placa Petri abierta. Medir ese volumen con un tubo Falcon de $50 \mathrm{~mL}$ estéril. Repetir esto para 5 placas Petri.

8. Esperar a que el medio de cultivo se solidifique y cerrar las placas Petri.

9. Sellar las placas con una tira de papel Parafilm y almacenar en el refrigerador.

Protocolo de muestreo e inoculación de microorganismos

1. Pasar un cotonito estéril por una superficie desde la cual se quiera muestrear microrganismos.

2. Pasar suavemente el cotonito sobre toda la superficie del medio de cultivo sólido de una placa Petri, realizando el método de siembra por estría.

3. Cerrar la placa Petri, sellar con papel parafilm y almacenarla en un lugar oscuro y que no esté expuesto a grandes fluctuaciones de temperatura y humedad.

4. Dejar la placa almacenada hasta que se observe crecimiento de microorganismos en forma de colonias.

\section{Protocolo de la técnica de tinción Gram}

1. Verter etanol sobre un vaso precipitado.

2. Utilizando la piseta de agua destilada, colocar una gota de agua en el centro de un portaobjeto.

3. Esterilizar el asa bacteriológica con etanol y fuego y flamear en el aire.

4. Abrir una placa que posea microorganismos y enfriar el asa bacteriológica en un sector del agar donde no existan colonias.

5. Contactar el asa bacteriológica con una colonia y arrastrar la colonia con el asa hasta depositarla sobre la gota de agua en el portaobjeto.

6. Mezclar la muestra con la gota de agua y esparcirla por la superficie del portaobjeto para obtener un frotis.

7. Fijar el frotis exponiéndolo a la llama del encendedor hasta que se seque. Evitar que el portaobjeto de vidrio se caliente no haciendo una exposición constante al fuego, si no que intermitente.

8. Cubrir el frotis completamente con cristal violeta (3 gotas) y dejar en reposo durante $3 \mathrm{~min}$.

9. Dejar escurrir el cristal violeta y botar el exceso de colorante con una cantidad mínima de agua.

10. Agregar sobre la muestra una solución de lugol (3 gotas) y dejar en reposo durante 2 min. 
11.Dejar escurrir el lugol y botar el exceso de colorante con una cantidad mínima de agua.

12. Lavar el lugol con alcohol-acetona y agua dejando escurrir suavemente, hasta que el frotis se decolore completamente.

13. Cubrir con colorante de contraste, safranina al $1 \%$, durante $1 \mathrm{~min}$.

14. Lavar con agua, dejar escurrir y secar a temperatura ambiente.

\subsection{Figuras}

Figura S1. Características visuales de los microorganismos cultivados en placas Petri con medio LB-glucosa-agar. A. Placa Petri con microorganismos provenientes de saliva de gato (estudiante F. V.). B. Colonia bacteriana de muestra proveniente de saliva de perro (estudiante R. P.). C. Colonia bacteriana de muestra proveniente de saliva de perro (estudiante R. P.). D. Colonia fúngica de muestra proveniente de saliva de perro (estudiante R. P.). Las características visuales de las muestras A-C corresponden a microorganismos tipo bacteria (colonias pequeñas, lisas, planas y de colores blanquecinos). Las características visuales de la muestra $D$ corresponden a microorganismos tipo hongo (colonias de mayor tamaño, rugosidad, crecimiento aéreo y color oscuro).

A

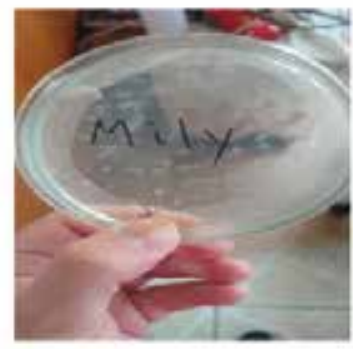

C

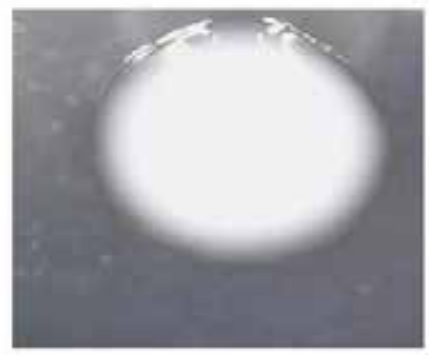

B

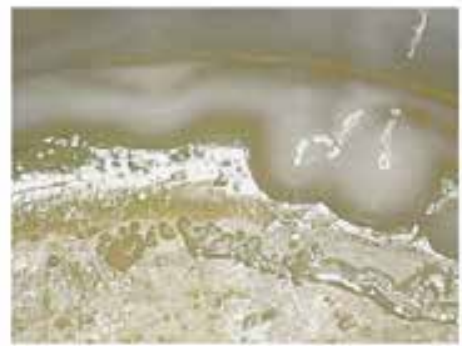

D

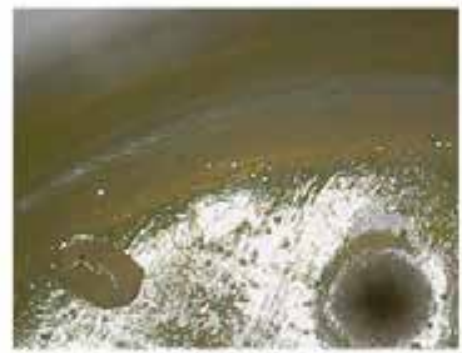

Fuente: Archivo de Iso autores. 
Figura S2. Frotis bacterianos teñidos con tinción Gram. A. Frotis de bacterias provenientes de muestra de saliva de perro (estudiante R. G.). B. Frotis de bacterias provenientes de muestra de suela de zapatilla (estudiante C. A.).

A

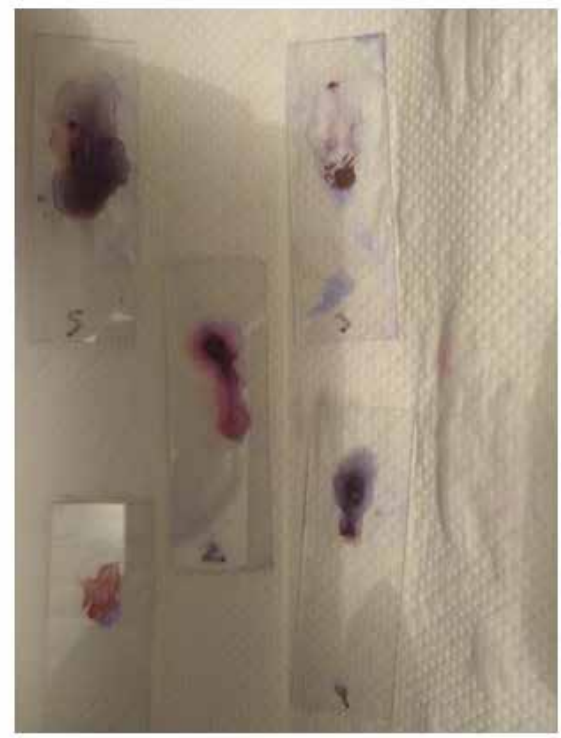

B

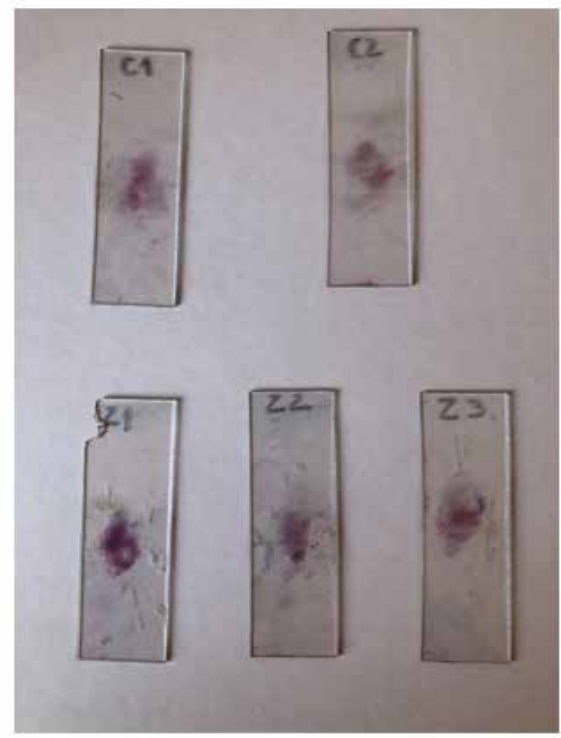

Fuente: Archivo de Iso autores. 
Figura S3. Esquema fotográfico del diseño experimental secuencial y los resultados obtenidos por el estudiante R. G. para responder la pregunta: ¿Cuál es el rango óptimo de temperatura de crecimiento de bacterias aisladas desde la superficie del fruto de un árbol de naranjas? A, Inóculo de bacterias provenientes de la superficie de naranjas de jardín, en medio sólido LB-glucosa. B, Diferentes lugares donde se depositaron las placas de cultivo durante tres días: jardín (condición 1), refrigerador (condición 2) y estante (condición 3). C, Registro de crecimiento bacteriano en el día 1 de cultivo en las diferentes condiciones. D, Registro de crecimiento bacteriano en el día 3 de cultivo en las diferentes condiciones.

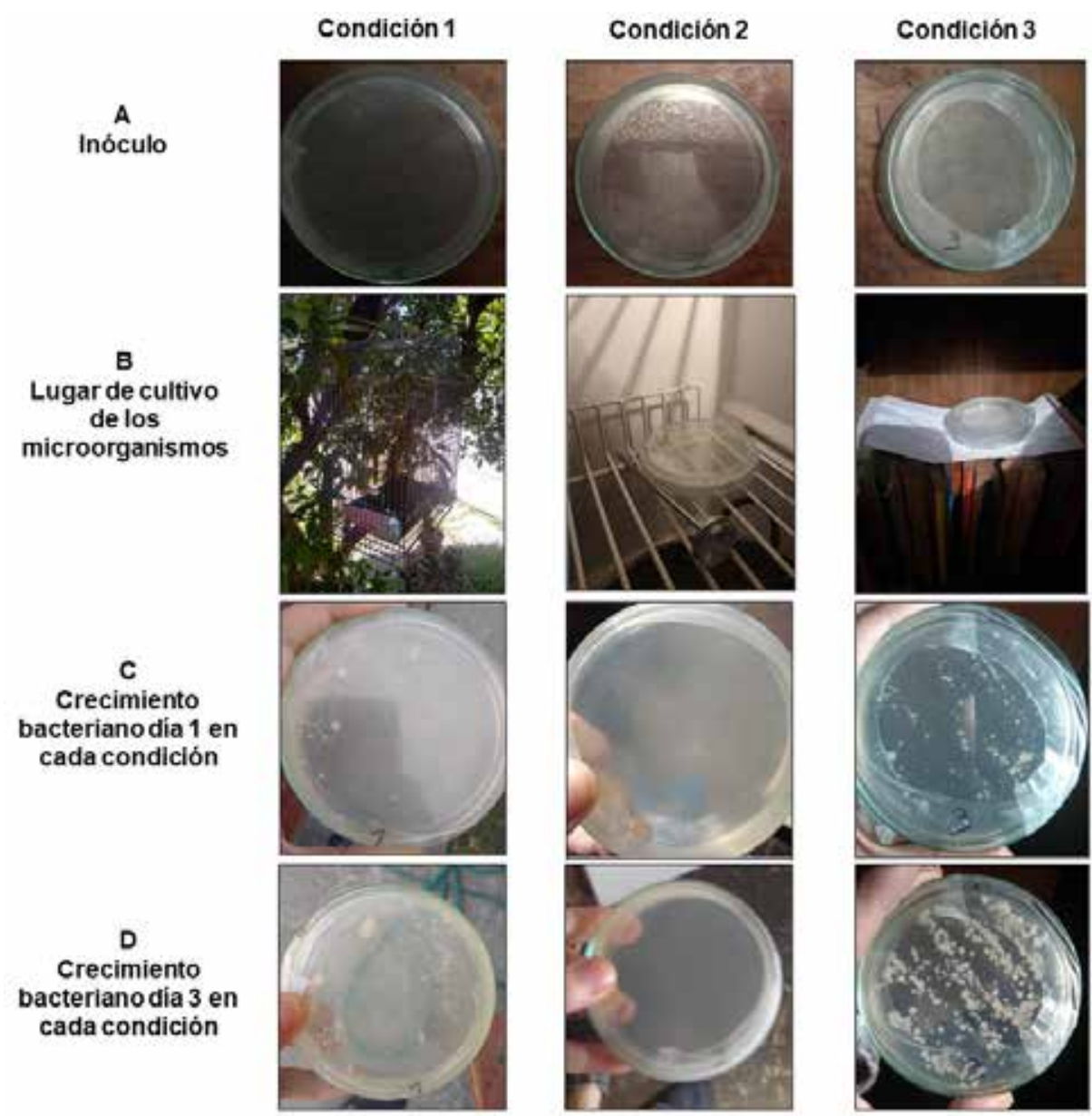

Fuente: Archivo de Iso autores. 
Figura S4. Resultados obtenidos experimentalmente por el estudiante R. P. para responder la pregunta: ¿Qué concentración de aceite esencial de jengibre inhibe el crecimiento de bacterias provenientes de la cavidad bucal de un humano adulto? En la figura de la izquierda se observa una placa de cultivo con discos de papel embebidos con aceite esencial de jengibre. En la figura de la derecha se observa una amplificación del área dentro del recuadro negro de la figura de la izquierda.
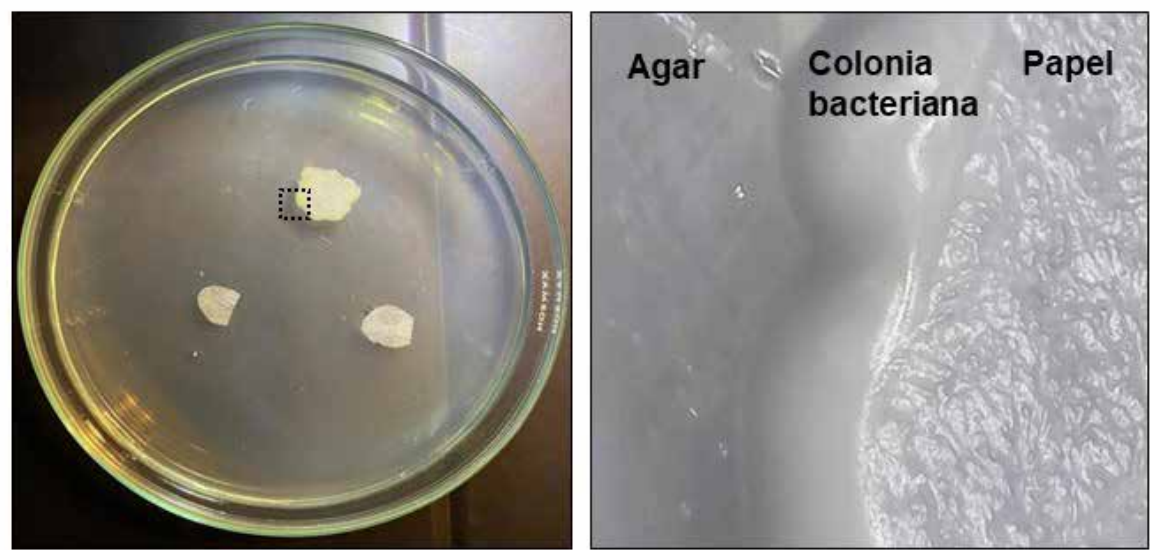

Fuente: Archivo de Iso autores.

Figura S5. Resultados obtenidos experimentalmente por el estudiante F. V. para responder la pregunta: ¿El hipoclorito de sodio y el alcohol poseen la misma capacidad antiséptica al aplicarlos sobre la superficie de un mesón? Se observan placas de cultivo con crecimiento bacteriano en las tres condiciones testeadas: control, hipoclorito de sodio $10 \% \mathrm{p} / \mathrm{v}$ y alcohol $75 \% \mathrm{p} / \mathrm{v}$.
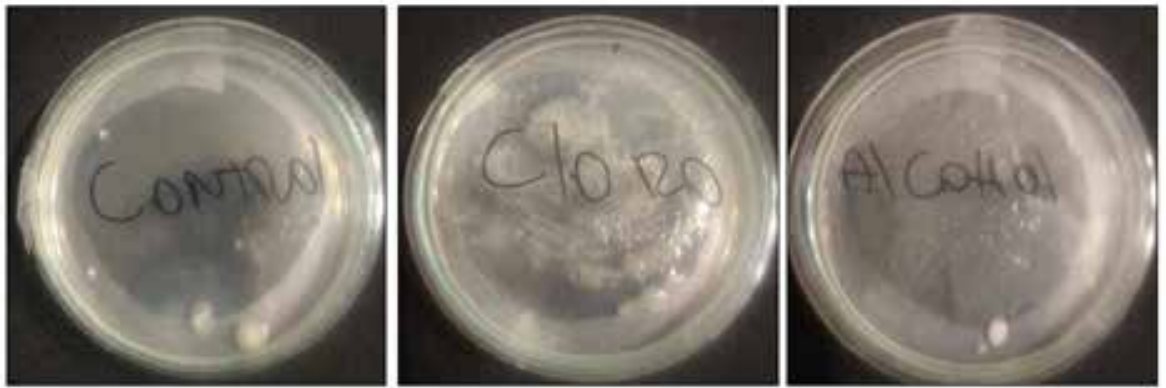

Fuente: Archivo de Iso autores.

\section{Cómo citar en APA:}

Vargas-Straube, M. J., Gutiérrez, J. C., Soto, J. F. e Isla, E. (2021). Aprendizaje de microbiología experimental en un formato virtual y en contexto de pandemia: una experiencia de implementación de actividades con la utilización de un set portátil en la formación de profesores de Biología y Ciencias Naturales. Revista Iberoamericana de Educación, 87(1), 49-71. https://doi.org/10.35362/ rie8714594 